been an increasing appreciation of the value of the progeny test. To assist breeders in this matter, the Hertfordshire Institute of Agriculture held on November 20 an auction sale, the catalogue of which is before us, of a number of young bulls, sons of "proven sires": this term connotes a bull whose unselected daughters are considered to have given a satisfactory yield. This enterprise is to be commended, though it is legitimate to wonder whether, in view of recent research, too much emphasis is not being laid upon the paternal grandsire of the heifers which the purchasers of these young bulls hope to breed. Greater value would be attached to the sale if daughters of proven sires were also on offer. Inevitably it has not been found possible to set a high standard, and critics of the catalogue should lay less emphasis on the fact that the average yields of the daughters of these seven proven sires have in no case reached 1,000 gallons, and rather be content with the fact that there has been made available an array of not only interesting but also reliable facts. There would, however, appear to be no excuse for describing as a proven sire a bull whose daughters' average yield was only 800 gallons and some 15 per cent less than that of their dams. Some officially recorded pigs were also sold. While this was not the first sale of this nature, the venture is likewise to be commended since it demonstrates a resolve on the part of some breeders to work, not by eye alone, but by scientific methods based principally on the rate of live-weight increase and carcass measurement. In view of the reorganisation of the pig industry in Great Britain, the movement is a timely one.

\section{The Smithfield Club}

THE effect of music upon fatted cattle, sheep and pigs will again be tried at the London Smithfield Club show in the Royal Agricultural Hall, Islington, on December 4-8 next. Milch cows have given a greater volume of milk under the influence of soothing music. This year, scientific investigators in animal foods and nutrition at Smithfield Show are to see whether beasts, which usually lose weight when appearing in fat stock exhibitions, cannot be made to maintain their rate of daily growth, when band music produced from gramophones and loudspeakers is played to keep them from becoming upset by the mobbing received from visitors. The King has entered 29 head of fat cattle, sheep and pigs, and the Prince of Wales, the Duke of Rutland, the Countess of Lonsdale, Lady Loder, Lord Danesbury and Lord Derby will also submit stock before the judges.

\section{Annual Report of the Meteorological Office}

THE annual report of the Director of the Meteorological Office to the Air Council for the year ended March 31, 1933, deals with the seventy-eighth year of the Meteorological Office. Details of the work of the various branches of the Office show that requests for meteorological information have again increased substantially in number over those received in the preceding year. The reorganised forecast branch at Adastral House, Kingsway, alone dealt with nearly sixteen thousand, and the numerous local centres of the aviation branch, with more than thirty-seven thousand, without counting weather reports passed to aircraft in flight. The British climatology division disposed of more than two thousand general or scientific inquiries for particulars of past weather, many of which were required for legal purposes. The report states that the year has been one of consolidation of the numerous changes and developments of the years since the War, and that the figures quoted illustrate the general appreciation shown of the increased facilities for the provision of meteorological information that have resulted therefrom. The advancement of meteorological knowledge by research has not been neglected as a result of attention to the immediate needs of the public, a number of special investigations being carried out, for example, at Kew; the importance of the work of the expedition to Fort Rae, North West Territories, Canada, in connexion with the programme of the Second International Polar Year, has led to the inclusion of a special section giving an account of that work. This shows that success has been achieved in maintaining autographic records of the magnetic elements, of atmospheric electricity and of the more ordinary meteorological quantities, as well as in the ambitious scheme of auroral study. Although great doubt had been felt as to the chances of retrieving instruments carried by sounding balloons, several have been recovered with records reaching well into the stratosphere.

\section{Secondary Sections of the British Grid System}

NEARLy all the British grid operates at a pressure of 132 kilovolts. Two sections operate at $66 \mathrm{kv}$. and $33 \mathrm{kv}$. respectively, and there are a few relatively unimportant sections which operate at smaller pressures. In a paper read to the Institution of Electrical Engineers on November 9, Mr. C. W. Marshall describes the 66 and $33 \mathrm{kv}$. sections. In the scheme of the Central Electricity Board, there are 221 miles of $66 \mathrm{kv}$. lines and 1,319 miles of $33 \mathrm{kv}$. lines. Unlike the main grid, these subsidiary lines are mainly used for transmission purposes. The standard conductor material from which they are made is steel-cored aluminium. The minimum clearance between any line conductor and the earth in still air under maximum temperature conditions $\left(50^{\circ} \mathrm{C}\right.$. $)$ is $20 \mathrm{ft}$. If they have to cross Post Office lines then, whenever possible, the P.O. lines are interrupted and cables substituted for them at the crossing. If this is not possible, a guard is provided under the power lines. In this case the minimum elearance between guard and Post Office lines is $\mathbf{3} \mathbf{f t}$. and between guard and power lines $4 \mathrm{ft}$. When the power lines cross a railway, the minimum clearance is $24 \mathrm{ft}$. above rail level. Lattice steel towers are the standard for all the Board's $66 \mathrm{kv}$. lines and, with one exception, for all the $33 \mathrm{kv}$. lines also. During the period of the activities of the Board, the development of cable technique has been very rapid. The first cables were made with solid dielectrics, the single core oil duct type came next, then the three 